\title{
CARBON MONOXIDE DIFFUSION AND VENTILATION IN UNDERGROUND GARAGE
}

\author{
Peng, S. B. ${ }^{1 *}-$ ChEn, Q. K. ${ }^{1}-$ GuO, B. Y. ${ }^{2}-$ PeI, G. H. $^{3}$ \\ ${ }^{I}$ School of Civil Engineering \& Architecture, Southwest Petroleum University, Chengdu \\ 610500, China \\ ${ }^{2}$ Petroleum Engineering School, Southwest Petroleum University, Chengdu 610500, China \\ ${ }^{3}$ School of Architectural Economics \& Business Administration, Hubei Business College, \\ Wuhan 430079, China \\ *Corresponding author \\ e-mail: shanbipeng@swpu.edu.cn; phone: +86-135-5039-6539
}

(Received $18^{\text {th }}$ Mar 2019; accepted $17^{\text {th }}$ May 2019)

\begin{abstract}
In this paper, the numerical simulation method of computational fluid dynamics (CFD) was combined with field experiment to explore the carbon monoxide (CO) diffusion and ventilation in an underground garage. Firstly, a finite-element model was set up for the garage, and used to simulate the CO concentration and air velocity. Then, the simulated results were proved valid against the data of field experiment. After that, a ventilation plan was designed with one fan running for $20 \mathrm{~min}$, three times a day in the rush hours. The simulation results show that this plan could not lower the $\mathrm{CO}$ concentration below the required level $\left(30 \mathrm{mg} / \mathrm{m}^{3}\right)$. Thus, the running time of the fan was extended to $30 \mathrm{~min}$ per time. It is found that the new ventilation plan could effectively control the $\mathrm{CO}$ concentration. Next, the third ventilation plan was developed with two fans running together for $10 \mathrm{~min}$, three times a day in the rush hours, and was proved as valid through simulation. Due to its advantage in power consumption, the third plan was identified as the optimal ventilation plan for the garage. The three-fan or four-fan ventilation plans were not considered because they must be noisier and costlier than the two-fan ventilation plan. Although the structure of underground garages (such as height, area, etc.) is different, most of them are common in high tightness and structural independence. The method mentioned in this study that using the necessary air parameters of measuring points in underground garage to simulate the status of airflow and $\mathrm{CO}$ concentration is effective.
\end{abstract}

Keywords: underground garage, airflow, pollution diffusion, air quality, numerical simulation

\section{Introduction}

Recent years has seen a growing concern about the air quality in underground garage. In such a highly closed space, it is difficult for the air inside the underground garage to exchange with ground air. The toxic gases emitted by cars in the garage may overaccumulate, such as carbon monoxide $(\mathrm{CO})$, nitrogen oxides $\left(\mathrm{NO}_{\mathrm{x}}\right)$ and hydrocarbons. Large quantities of harmful gases will reduce the air quality and human body comfort even lead disease or death. And among them, produced $\mathrm{CO}$ is more toxic and concentrated than the other harmful gases in process of vehicles cold starting and idle speeding (Chen, 2001). Hence, this paper attempts to control CO concentration by ventilation in order to solve the problem of air quality.

To control CO concentration, the key lies in the relationship between air flow and pollutant distribution, as the air quality in underground garage may vary with the ventilation conditions. So far, this relationship has been mainly explored through field experiment and numerical simulation. The typical field experiments are reviewed as follows.

$\mathrm{Xu}$ (2015) investigated the flow field in underground space by tracer gas method, revealing that different ventilation states lead to different distribution of tracer gas. Kierat et 
al. (2018) applied the same method to assess the exposure of indoor breathing air, and found that the exposure of indoor air pollution is affected by the air flow interaction in the breathing zone. With the aid of federal equivalent method, Zhao et al. (2017) studied the seasonal concentrations of PM 2.5 and other pollutants in underground garage, concluding that natural ventilation alone cannot dilute particles effectively in the residential garage. Targeting a wavy air-water interface, Buckley and Verson (2017) measured the airflow through laser induced fluorescence (LIF) flow visualization and particle image velocimetry (PIV). Zhang et al. (2008) adopted the hydroxybenzene reagent method to capture the concentration of formaldehyde, and discovered that the air quality is severely affected by the emission of materials in the compartments of many compact cars sold in China.

The numerical simulation has been increasingly employed recently, thanks to its low consumption of manpower and materials. The fluid state is usually simulated by the computational fluid dynamics (CFD). For instance, Liu et al. (2019a, 2018, 2016a, b), Yong et al. (2017) studied flow characteristics of gas in a pipe and analyzed the formation mechanism of trailing oil. Kurnia et al. (2014) numerically simulated the methane dispersion in an underground mine. Wang et al. (2016) explored the storage temperature field in a non-ventilated underground granary using the CFD. Choi et al. (2013) relied on the CFD to investigate the hydrogen leakage of cars in underground garage. Papakonstantinou et al. (2003) examined the air quality and CO dispersion of underground garage through the numerical method and experiment. Xue and Ho (2000) set up a model of underground garage and simulated CO diffusion and heat conduction. Wang et al. (2009) simulated the diffusion of dust at underground power house. Widiatmojo et al. (2013) evaluated the gas diffusion of turbulent flow in mine ventilation system by numerical simulation. Hong et al. (2010) studied the influence of branch tunnels on CO diffusion at underground power house. Bai et al. (2016) probed into the flow field of a train running to the rescue station through both experiment and simulation. Wang et al. (2017) simulated and calculated how forced ventilation affects the water spray and dust suppression on the work face of coal mine. Wang and Ren (2013) carried out a CFD analysis on the behavior of dust flow and air flow above an underground bin. Bascompta et al. (2016) and Liu et al. (2019b) tackled the impacts of ventilation layout on the environment using the geographical information system (GIS).

Concerning pollutant distribution and flow field in closed space, the existing studies either resort to CFD simulation or rely on field experiment. There are relatively few studies that combine these two approaches. To make up for this gap, the CFD simulation and field experiment are combined in this paper to discuss the $\mathrm{CO}$ concentration at an underground garage. The experimental data help determine parameters of boundary conditions, and verify the availability of the modelling, thus ensuring the simulation accuracy.

Generally, the structure of underground garages is different due to various requirements, however they are common in their special characteristics such as high air tightness and structural independence. Although the results of this real case may not apply to all cases, the proposed method in this paper that combines the CFD and field experiment is proved available. The ventilation analysis of different underground garages only needs to adjust the geometry model and the relevant environmental parameters.

\section{Methodology}

\section{Research object}


This paper tackles a real problem in an underground garage within a university of southwestern China's Sichuan Province. The photos and model of the garage are presented in Figure 1. The cars in the garage were defined as pollution sources.

As shown in Figure 1, the $48 \mathrm{~m} \times 45 \mathrm{~m} \times 3 \mathrm{~m}(\mathrm{~L} \times \mathrm{W} \times \mathrm{H})$ garage has about 200 parking spaces, 3 aisles (b d) and one secure channel (f). Under pressure difference, a limited amount of fresh air can enter the garage through ventilation shafts (e). The airflow in the garage is driven by the thermal and wind pressures from the natural ventilation system, and the mechanical force of fans.

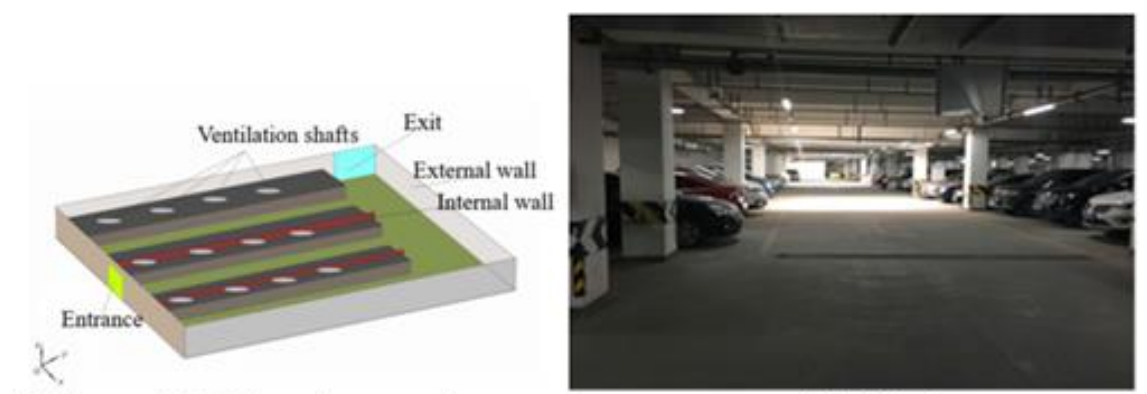

(a) The model of the underground garage

(b) Aisle 1

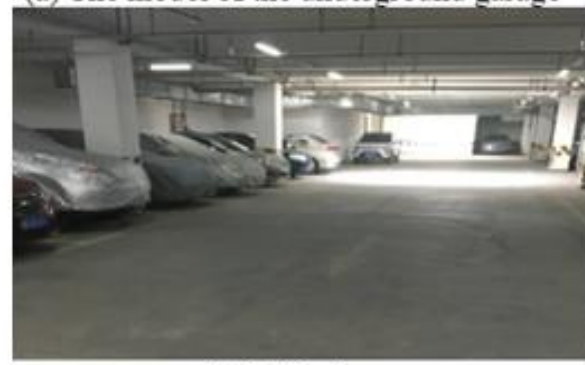

(c) Aisle 2

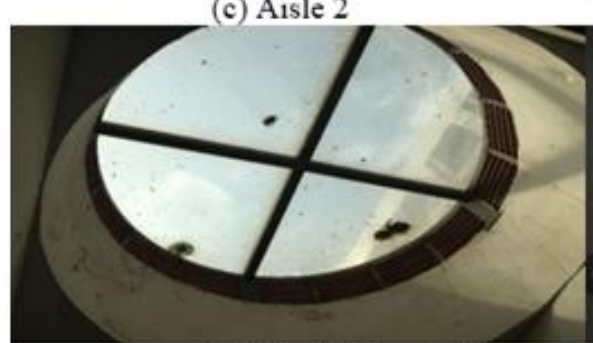

(e) Ventilation shaft

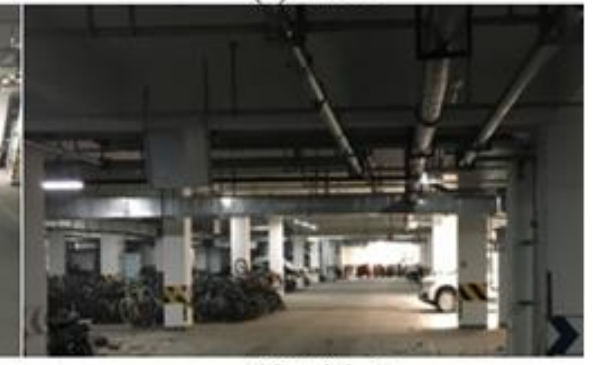

(d) Aisle 3

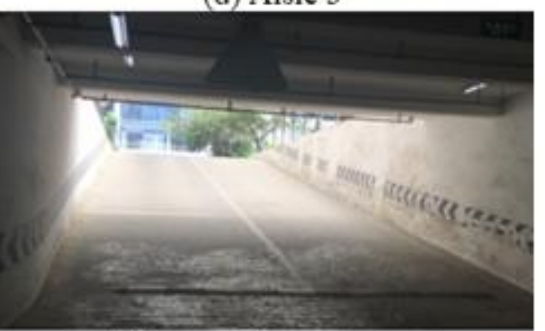

(f) Secure channel

Figure 1. The model ( $a$ ) and photos $(b \sim g)$ of the underground garage

The measured pressure is positive at each ventilation shaft, and negative at the entrance. This means the fresh air flows into the garage from the entrance and leaves from the shafts. The flowing process is illustrated in Figure 2.

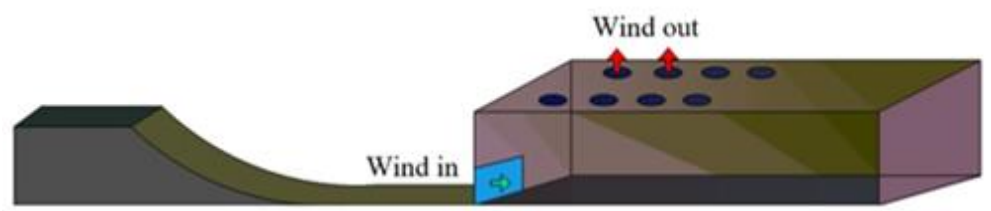

Figure 2. The flowing process in the underground garage 
The space of underground garage is divided into three areas by two internal walls with four exhaust fans located in different positions (Fig. 3). Each fan runs at 500 750 rpm, propelling 32,000 42,000 $\mathrm{m}^{3}$ fresh air per hour.

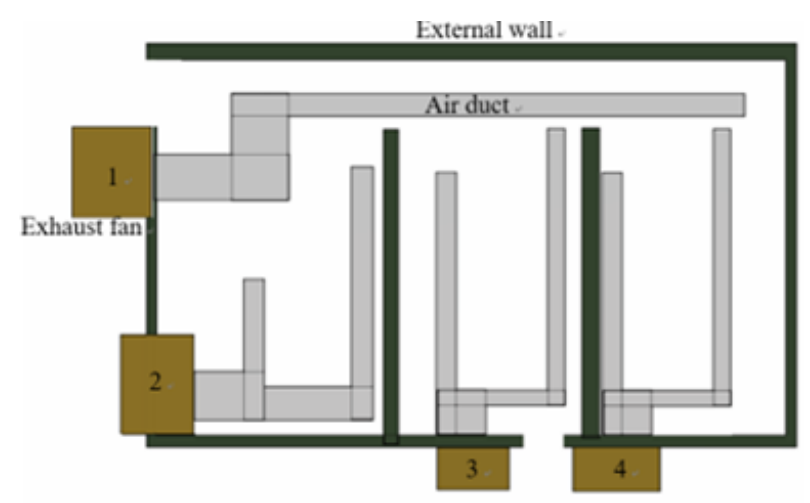

Figure 3. The layout plan of the underground garage

In this research, several ventilation conditions were simulated by the CFD, and verified by the experimental data. On this basis, the most cost-effective control plan for $\mathrm{CO}$ concentration was selected as the optimal solution.

\section{Field experiment}

The underground garage was divided into four areas for measurement, namely, the parking lots (D), secure channel (A), aisles (B), plus the entrance and exit (C) (Fig. 4). The CO concentration was measured in rush hours (i.e. $8 \mathrm{am}, 12 \mathrm{pm}$ and $2 \mathrm{pm}$ ) as well as at $10 \mathrm{am}$ and $4 \mathrm{pm}$. The data collected at two hours later were taken as control data.

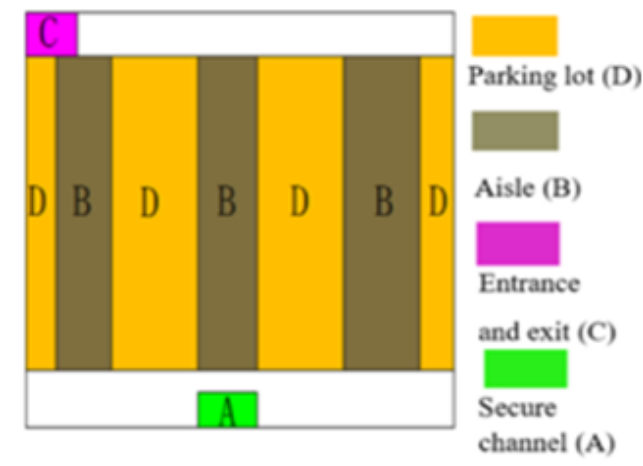

Figure 4. The measuring points in the underground garage

The air velocity and $\mathrm{CO}$ concentration were respectively measured by a hot-wire anemometer (error: \pm 0.03 ; range: $0.15 \sim 30 \mathrm{~m} / \mathrm{s}$ ) and a Z500XP CO sensor (error: \pm 0.05; range: 0 300 ppm) (Fig. 5). Before measuring the air velocity, the probe of the hot-wire anemometer should be set perpendicularly to the wind direction. During the measurement, the $\mathrm{CO}$ sensor should be turned on and placed at the measuring point for a few minutes. 


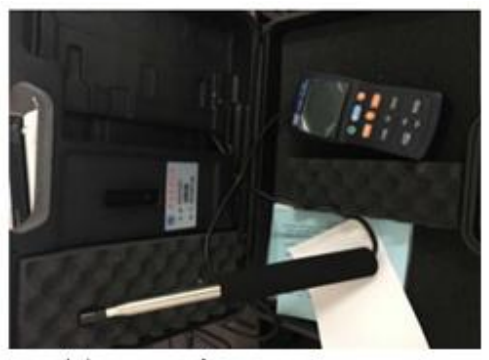

(a) Hot-wire anemometer

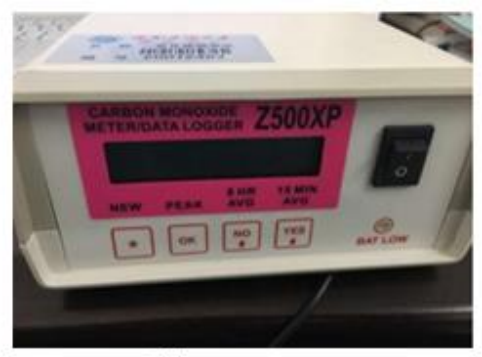

(b) $\mathrm{CO}$ sensor

Figure 5. Measuring instruments

The CO concentration of the aisles must be strictly controlled to protect the health of pedestrians. The three aisles in the underground garage were numbered as aisle 1, aisle 2 and aisle 3. Five measuring points were arranged in the middle of each aisle at an equal interval from the entrance to the exist (Fig. 6).

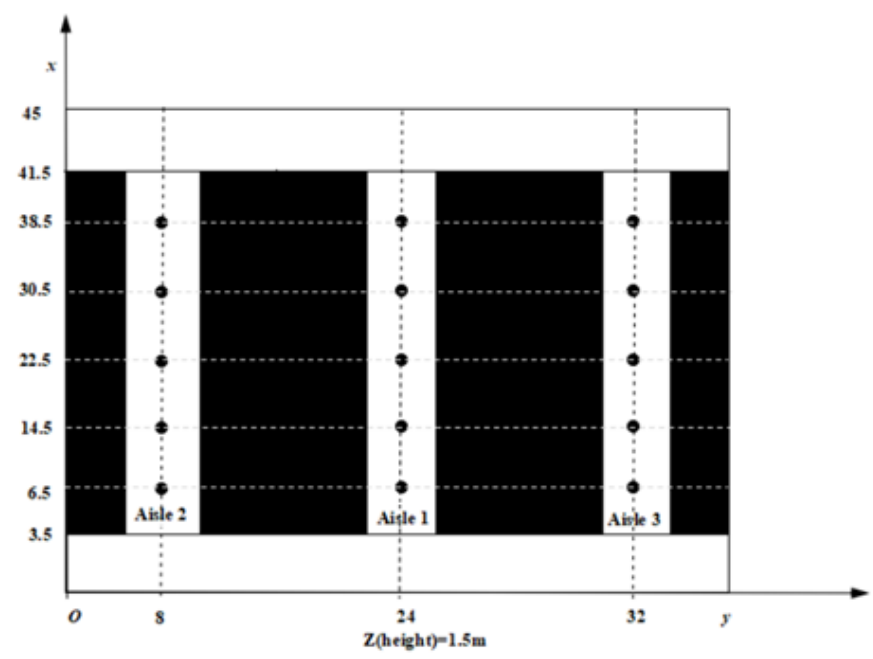

Figure 6. The aisles and measuring points

To investigate whether the outside environment will affect the airflow and CO diffusion in the underground garage, air velocity and $\mathrm{CO}$ concentration are measured respectively at each measuring point and outdoor for several times in one week. The mean of the five results was taken as the final value, when record the CO concentration, the unit "ppm" was converted into " $\mathrm{mg} / \mathrm{m}^{3}$ ":

$$
\frac{m g}{m^{3}}=\frac{M}{22.4} \times \mathrm{pp} m \times \frac{273}{273+T} \times \frac{P}{101325}
$$

where $\mathrm{T}$ is the measured temperature; $\mathrm{P}$ is the measured pressure (Bar); $\mathrm{M}$ is the molecular mass of the measured gas.

The measured data are recorded in Tables 1 and 2. The results from Tables 1 and 2 directly show the $\mathrm{CO}$ concentration and air velocity of each measuring point and outdoor. It can be found in Table 1 that the CO concentration various from $1.8 \mathrm{mg} / \mathrm{m}^{3}$ to 
$2.6 \mathrm{mg} / \mathrm{m}^{3}$ but the $\mathrm{CO}$ concentration of underground garage is much higher. It proofs that $\mathrm{CO}$ concentration of underground garage is mainly affected by the parking vehicles, low $\mathrm{CO}$ concentration of outdoor cannot greatly affect that of underground garage.

Table 1. The CO concentration in different areas $\left(\mathrm{mg} / \mathrm{m}^{3}\right)$

\begin{tabular}{|c|c|c|c|c|c|c|}
\hline Outdoor & & Point 1 & Point 2 & Point 3 & Point 4 & Point 5 \\
\hline \multirow{3}{*}{2.6} & Aisle 1 & 34 & 33 & 43 & 32 & 25 \\
\hline & Aisle 2 & 11 & 21 & 27 & 23 & 16 \\
\hline & Aisle 3 & 13 & 18 & 31 & 23 & 21 \\
\hline \multirow{3}{*}{2.1} & Aisle 1 & 33 & 30 & 41 & 31 & 25 \\
\hline & Aisle 2 & 13 & 22 & 29 & 25 & 20 \\
\hline & Aisle 3 & 14 & 18 & 30 & 25 & 18 \\
\hline \multirow{3}{*}{1.8} & Aisle 1 & 35 & 33 & 42 & 29 & 23 \\
\hline & Aisle 2 & 15 & 20 & 31 & 25 & 17 \\
\hline & Aisle 3 & 17 & 20 & 31 & 24 & 19 \\
\hline \multirow{3}{*}{2.0} & Aisle 1 & 34 & 32 & 38 & 31 & 26 \\
\hline & Aisle 2 & 12 & 21 & 32 & 26 & 19 \\
\hline & Aisle 3 & 15 & 19 & 29 & 27 & 21 \\
\hline \multirow{3}{*}{2.1} & Aisle 1 & 37 & 34 & 37 & 28 & 24 \\
\hline & Aisle 2 & 14 & 19 & 30 & 27 & 18 \\
\hline & Aisle 3 & 16 & 23 & 29 & 24 & 20 \\
\hline \multirow{3}{*}{1.8} & Aisle 1 & 36 & 35 & 39 & 30 & 25 \\
\hline & Aisle 2 & 12 & 20 & 33 & 24 & 19 \\
\hline & Aisle 3 & 16 & 20 & 32 & 27 & 22 \\
\hline \multirow{3}{*}{1.9} & Aisle 1 & 35 & 34 & 40 & 29 & 27 \\
\hline & Aisle 2 & 14 & 17 & 28 & 25 & 17 \\
\hline & Aisle 3 & 14 & 22 & 29 & 25 & 19 \\
\hline
\end{tabular}

Table 2. The air velocity in different areas $(\mathrm{m} / \mathrm{s})$

\begin{tabular}{c|c|c|c|c|c|c}
\hline Outdoor & & Point 1 & Point 2 & Point 3 & Point 4 & Point 5 \\
\hline \multirow{3}{*}{$2.5 \mathrm{~m} / \mathrm{s}$} & Aisle 1 & 0.39 & 0.22 & 0.19 & 0.16 & 0.15 \\
& Aisle 2 & 0.09 & 0.1 & 0.1 & 0.16 & 0.14 \\
& Aisle 3 & 0.05 & 0.07 & 0.18 & 0.21 & 0.11 \\
\hline \multirow{3}{*}{$3.5 \mathrm{~m} / \mathrm{s}$} & Aisle 1 & 0.41 & 0.21 & 0.21 & 0.17 & 0.17 \\
& Aisle 2 & 0.08 & 0.12 & 0.11 & 0.15 & 0.15 \\
& Aisle 3 & 0.07 & 0.05 & 0.17 & 0.21 & 0.12 \\
\hline \multirow{3}{*}{$2.7 \mathrm{~m} / \mathrm{s}$} & Aisle 1 & 0.38 & 0.23 & 0.2 & 0.15 & 0.15 \\
& Aisle 2 & 0.08 & 0.12 & 0.11 & 0.13 & 0.16 \\
& Aisle 3 & 0.06 & 0.08 & 0.2 & 0.2 & 0.14 \\
\hline \multirow{3}{*}{$5 \mathrm{~m} / \mathrm{s}$} & Aisle 1 & 0.4 & 0.2 & 0.22 & 0.16 & 0.14 \\
& Aisle 2 & 0.09 & 0.11 & 0.13 & 0.19 & 0.15 \\
& Aisle 3 & 0.04 & 0.1 & 0.19 & 0.18 & 0.13 \\
\hline \multirow{3}{*}{$4.7 \mathrm{~m} / \mathrm{s}$} & Aisle 1 & 0.37 & 0.21 & 0.17 & 0.18 & 0.13 \\
& Aisle 2 & 0.07 & 0.09 & 0.09 & 0.15 & 0.18 \\
& Aisle 3 & 0.05 & 0.06 & 0.18 & 0.19 & 0.12 \\
\cline { 5 - 6 } $3.2 \mathrm{~m} / \mathrm{s}$ & Aisle 1 & 0.41 & 0.22 & 0.19 & 0.16 & 0.15 \\
& Aisle 2 & 0.1 & 0.11 & 0.12 & 0.17 & 0.17 \\
& Aisle 3 & 0.07 & 0.07 & 0.17 & 0.21 & 0.14 \\
\hline \multirow{3}{*}{$5.6 \mathrm{~m} / \mathrm{s}$} & Aisle 1 & 0.4 & 0.24 & 0.2 & 0.17 & 0.16 \\
& Aisle 2 & 0.07 & 0.12 & 0.11 & 0.16 & 0.17 \\
& Aisle 3 & 0.06 & 0.06 & 0.19 & 0.22 & 0.12 \\
\hline
\end{tabular}


With air velocity ranging from 2.5 to $5.6 \mathrm{~m} / \mathrm{s}$, the air flow of each measuring point is stable within $0.5 \mathrm{~m} / \mathrm{s}$. This fully demonstrated that the underground garage is a greatly sealed space. Although the environmental factor of outdoor has impact on airflow of underground garage, it affects the entrance and exit which are set as boundary in simulation more. Hence, it is just need change the parameter of boundary condition when simulate the air status of underground garage.

\section{CFD numerical simulation}

\section{(1) Governing equations}

The governing equations include the conservations of mass and momentum (Dokos, 2017; Su et al., 2019):

Conservation of mass:

$$
\frac{\partial P}{\partial \mathrm{t}}+\frac{\partial\left(\rho \mu_{x}\right)}{\partial x}+\frac{\partial\left(\rho \mu_{y}\right)}{\partial y}+\frac{\partial\left(\rho \mu_{z}\right)}{\partial z}=0
$$

Conservation of momentum:

$$
U_{j}=\frac{\partial U_{i}}{x_{j}}=-\frac{1}{\rho} \frac{\partial \rho}{x_{i}}+\frac{\partial}{\partial x_{i}}\left(v t \frac{\partial U_{i}}{x_{j}}-U_{i} U_{j}\right)
$$

\section{(2) Model selection}

There are many CFD models with different functions and applicable scopes.

There are some models can be selected in CFD, the function of each model is different and can be used in various industries. In terms of function, the models were summarized by Varga et al. (2017) standard K-epsilon (k- $\varepsilon$ ), Re-Normalisation Group (RNG) k- $\varepsilon$, and realizable k- $\varepsilon$. Among them, the standard k- $\varepsilon$ model is chosen in our research. The two basic transport equations and the component transport equation of this model can be respectively expressed as:

$$
\begin{gathered}
U_{j} \frac{\partial U_{i}}{\partial x_{j}}=\frac{\partial}{\partial x_{j}}\left(\frac{v t}{\sigma_{k}} \frac{\partial k}{\partial x_{j}}\right)+v t\left(\frac{\partial U_{i}}{\partial x_{j}}+\frac{\partial U_{j}}{\partial x_{i}}\right) \frac{\partial U_{i}}{\partial x_{j}}-\varepsilon \\
U_{j} \frac{\partial \varepsilon}{\partial x_{j}}=-\frac{\partial}{\partial x_{j}}\left(\frac{v t}{\sigma_{k}} \frac{\partial k}{\partial x_{j}}\right)+\frac{\varepsilon}{k}\left[C_{\varepsilon 1} v t\left(\frac{\partial U_{i}}{\partial x_{j}}+\frac{\partial U_{j}}{\partial x_{i}}\right) \frac{\partial U_{i}}{\partial x_{j}}-C_{\varepsilon 2} \varepsilon\right] \\
\frac{\partial \mu_{j}}{\partial x_{j}}=\frac{\partial}{\partial x_{j}} D \frac{\partial C_{i}}{\partial x_{j}}-C_{\varepsilon 2} \varepsilon
\end{gathered}
$$

where $\mu_{\mathrm{x}}, \mu_{\mathrm{y}}$ and $\mu_{\mathrm{z}}$ are the velocity component in the $\mathrm{x}, \mathrm{y}$ and $\mathrm{z}$ directions, respectively $(\mathrm{m} / \mathrm{s}) ; \mathrm{t}$ is the time $(\mathrm{s}) ; \rho$ is the density $\left(\mathrm{kg} / \mathrm{m}^{3}\right) ; \mathrm{i}$ and $\mathrm{j}$ are the serial number of the three directions and the $3 \mathrm{D}$ coordinates $(\mathrm{i}=1,2,3 ; \mathrm{j}=1,2,3) ; \mathrm{U}_{\mathrm{j}}$ is the mean velocity of the three directions; $\mu_{\mathrm{i}}$ and $\mu_{\mathrm{j}}$ are the pulsating velocity components of different directions; $\mathrm{V}_{\mathrm{t}}$ is turbulence viscosity coefficient; $\mathrm{C}_{\mathrm{i}}$ is the per-unit $\mathrm{CO}$ concentration; $\mathrm{S}_{\mathrm{i}}$ is the pollution source; $\mathrm{D}$ is the diffusion coefficient $(\mathrm{m} / \mathrm{s})$. 


\section{(3) Computational domain and meshing}

Since its birth in 1953, numerical simulation has been steadily improved. In 1973, Bruce and Peaceman simulated the 1D unsteady and radial flow of the gas phase. With the rapid development of computer science, the CFD has proliferated rapidly to various industries. Considering its complex structure, the underground garage was simplified into a collection of regular geometric figures. The parking spaces and internal walls were treated as equal size rectangles, while the ventilation shafts were considered as equal size circles. The entire garage was meshed into 224,094 tetrahedral grids (Fig. 7).
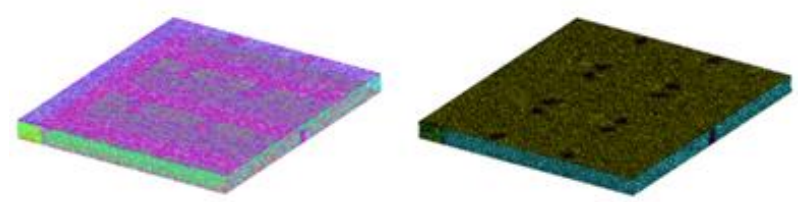

Figure 7. The grid model of the underground garage

\section{(4) Boundary conditions and gas components}

The entrance, the exit and the ventilation shafts were considered as velocity boundaries. The air velocity measured at such boundaries was $1 \mathrm{~m} / \mathrm{s}$ in the experiment. The rectangles in the grid model, which represent the parking spaces, are set as pollution sources. The standard wall function was adopted.

The parameter of fluid (i.e. the gas components in underground garage) are necessary, owing to the use of the component transport equation in the simulation. The gas components be added were determined as $\mathrm{CO}, \mathrm{CO}_{2}, \mathrm{~N}_{2}, \mathrm{O}_{2}$ and water vapor. The parameter of each gas component was set to be same as the air, except $\mathrm{CO}$ and $\mathrm{CO}_{2}$, which is a source of pollution. The mass diffusivity of $\mathrm{CO}$ was obtained from the test: $1.0368 \mathrm{~m}^{2} / \mathrm{h}$.

After defining the boundary conditions, the $\mathrm{CO}$ concentration and air velocity were simulated under natural ventilation. Since the breathing height of a person is about $1.5 \mathrm{~m}$, the plane of "axis $\mathrm{z}=1.5 \mathrm{~m}$ " was selected to output the simulation results.

\section{Results and discussion}

\section{Validation and analysis}

The simulation results were verified against the data of field experiment, aiming to verify that they are not outliers.

\section{(1) Validation of air velocity}

Figure 8 shows the contour of the simulated air velocities and Figure 9 presents the simulated air velocities of each aisle. Obviously, aisle 1, which is the closest to the entrance, had the fastest air velocity among all aisles. Besides, the air velocity decreased with the growth in the distance to the entrance. In aisles 2 and 3, the air velocities were stabilized between $0 \mathrm{~m} / \mathrm{s}$ and $0.5 \mathrm{~m} / \mathrm{s}$. 


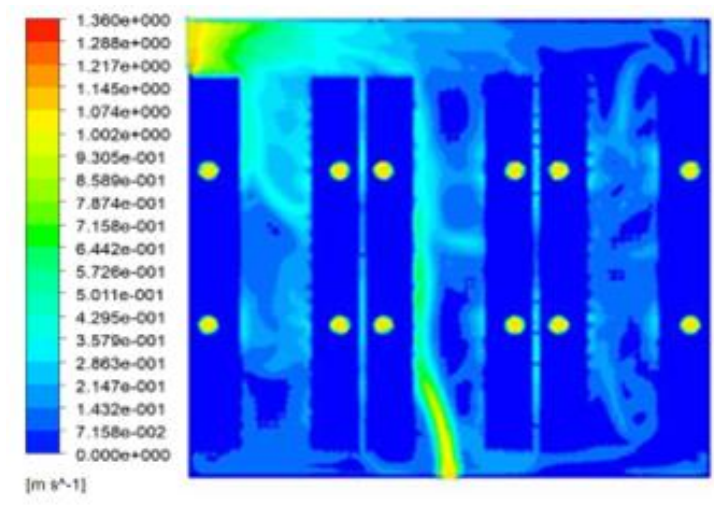

Figure 8. Contour of air velocity $(\mathrm{m} / \mathrm{s})$

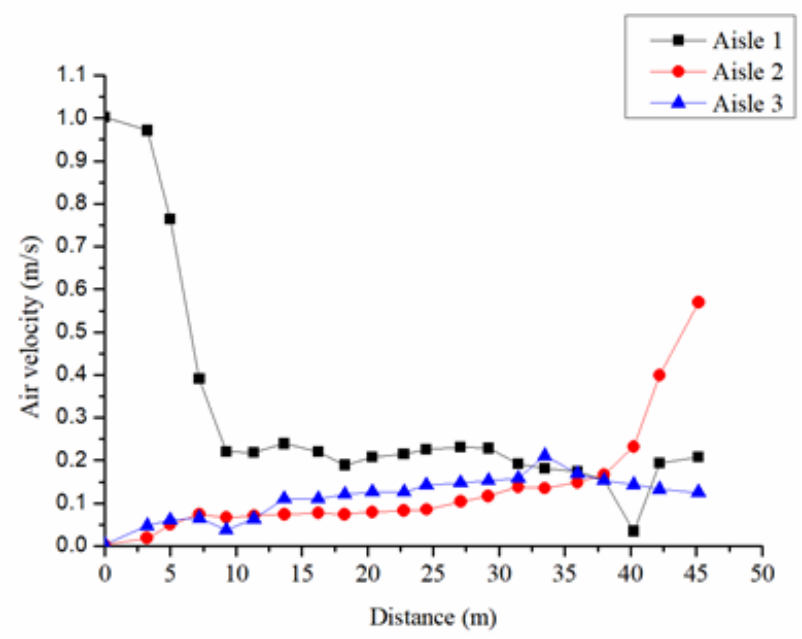

Figure 9. Simulated air velocity of each aisle $(\mathrm{m} / \mathrm{s})$

Figure 10 compares the simulated data and experimental data on the air velocity at each measuring point of each aisle. During the experiment, the air velocity of each aisle was measured at 12 points, which were arranged at an equal interval from the entrance to the exit. Distance on the transverse axis of the figures below is the distance between measuring point and wall of where secure channel located. Each experimental value was taken from the mean of five repeated measurements. As shown in Figure 10, the simulation error is obviously acceptable.

\section{(2) Validation of $\mathrm{CO}$ concentration}

The $\mathrm{CO}$ concentration of the underground garage was simulated under natural ventilation. The simulated results are shown in Figures 11 and 12 .

During the field experiment, the $\mathrm{CO}$ concentration at each of the five measuring points of each aisle was measured at the five time points of $8 \mathrm{am}, 10 \mathrm{am}, 12 \mathrm{pm}, 2 \mathrm{pm}$ and $4 \mathrm{pm}$, and compared with the corresponding simulated value. The measured $\mathrm{CO}$ concentrations of each area and the rush hour $\mathrm{CO}$ concentrations at each measuring point are listed in Tables 3 and 4, respectively. 


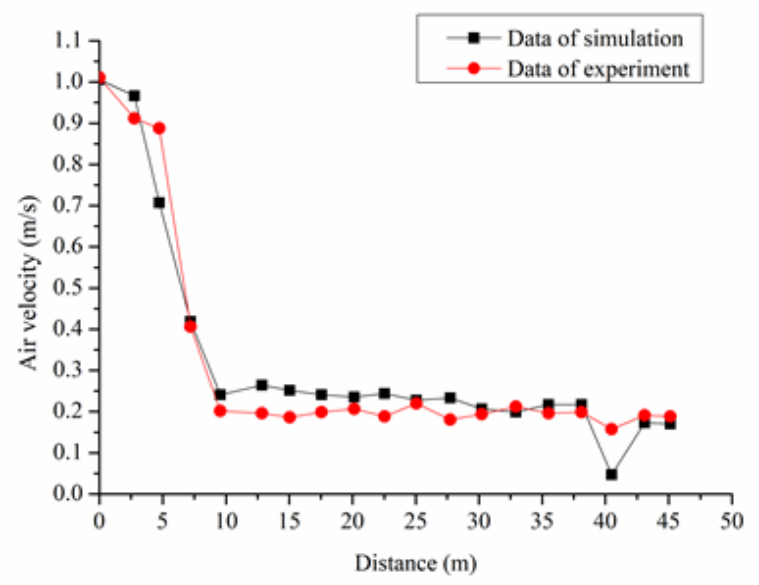

Figure 10. Simulated air velocities vs. experimental air velocities
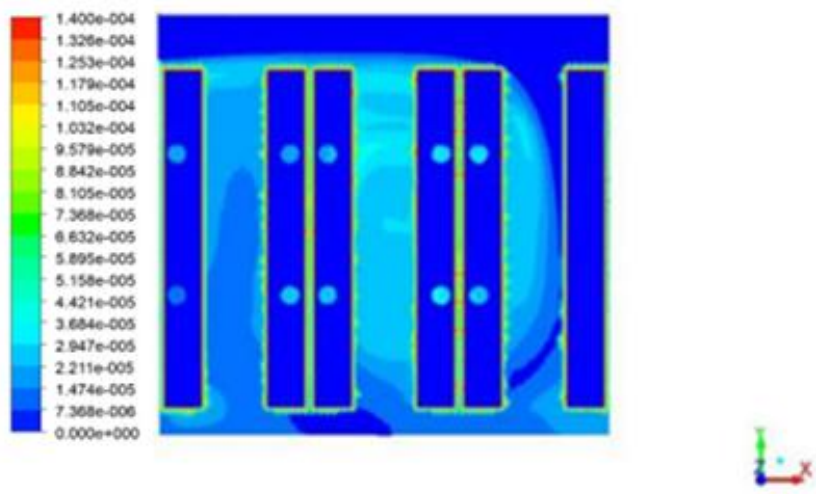

Figure 11. Contour of simulated CO concentration $\left(\mathrm{mg} / \mathrm{m}^{3}\right)$

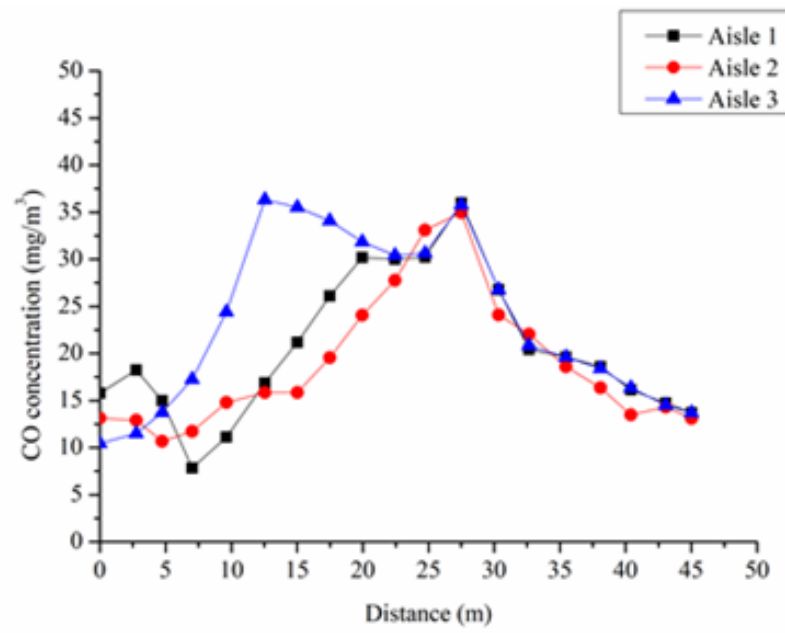

Figure 12. Simulated CO concentration of each aisle $\left(\mathrm{mg} / \mathrm{m}^{3}\right)$

In rush hour $8 \mathrm{am}, 12 \mathrm{am}$, and $2 \mathrm{pm}$, the $\mathrm{CO}$ concentration in $\mathrm{B}$ and D increased obviously, but in A and $\mathrm{C}$, the $\mathrm{CO}$ concentration changed slightly. This is because the 
area $\mathrm{A}$ and $\mathrm{C}$ is close to the outside and is easier to obtain the gas exchange. Area $\mathrm{B}$ is the pollution source and the $\mathrm{CO}$ concentration in area $\mathrm{B}$ that consists of three aisles is major object in the analysis. By comparing the data from Tables 3 and 4, it is obtained that in the underground garage, the $\mathrm{CO}$ concentration of measuring points will be affected by the inlet and outlet. Hence, the $\mathrm{CO}$ is mainly distributed in center underground garage which means the max $\mathrm{CO}$ concentration appears in this area.

Table 3. The CO concentration in different areas $\left(\mathrm{mg} / \mathrm{m}^{3}\right)$

\begin{tabular}{c|c|c|c|c|c}
\hline Areas & 8am & $\mathbf{1 0 a m}$ & $\mathbf{1 2 p m}$ & $\mathbf{2 p m}$ & $\mathbf{4 p m}$ \\
\hline A & 17 & 15 & 20 & 16 & 21 \\
B & 42 & 32 & 40 & 44 & 31 \\
C & 14 & 13 & 15 & 14 & 12 \\
D & 40 & 32 & 38 & 42 & 33 \\
\hline
\end{tabular}

Table 4. The rush hour CO concentration at each measuring point $\left(\mathrm{mg} / \mathrm{m}^{3}\right)$

\begin{tabular}{c|c|c|c|c|c}
\hline Areas & Point 1 & Point 2 & Point 3 & Point 4 & Point 5 \\
\hline Aisle 1 & 35 & 33 & 40 & 30 & 25 \\
Aisle 2 & 13 & 20 & 30 & 25 & 18 \\
Aisle 3 & 15 & 20 & 30 & 25 & 20 \\
\hline
\end{tabular}

As can be seen in Table 4, the $\mathrm{CO}$ concentration was higher in aisle 1 than in the other two aisles. The CO level in aisle 1 was above the required level of $30 \mathrm{mg} / \mathrm{m}^{3}$, indicating that more fresh air should be introduced to this aisle. The simulated and experimental data of the three aisles are compared in Figures 13-15.

The above figures show that the simulated data of each aisle deviated from the experimental data by only 5 20\%, far lower than the allowable error (20\%) for engineering application. Thus, the simulation results are proved as valid.

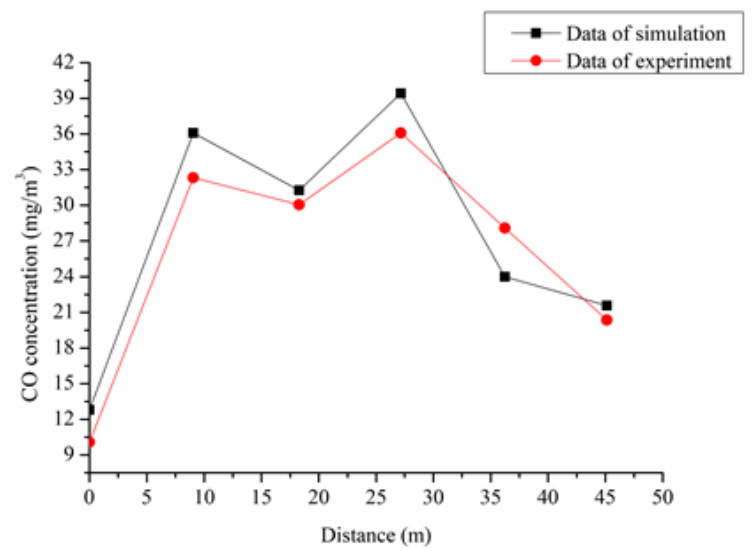

Figure 13. Simulated CO concentrations vs. experimental CO concentrations in aisle 1 


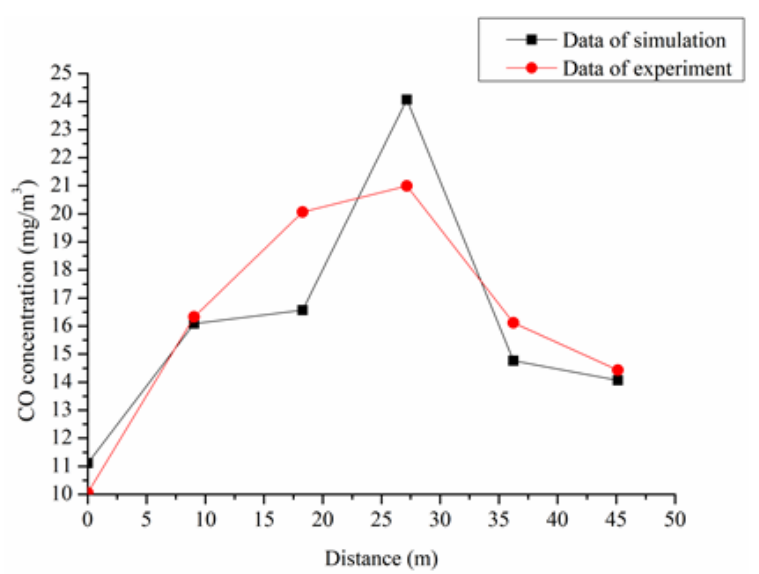

Figure 14. Simulated CO concentrations vs. experimental CO concentrations in aisle 2

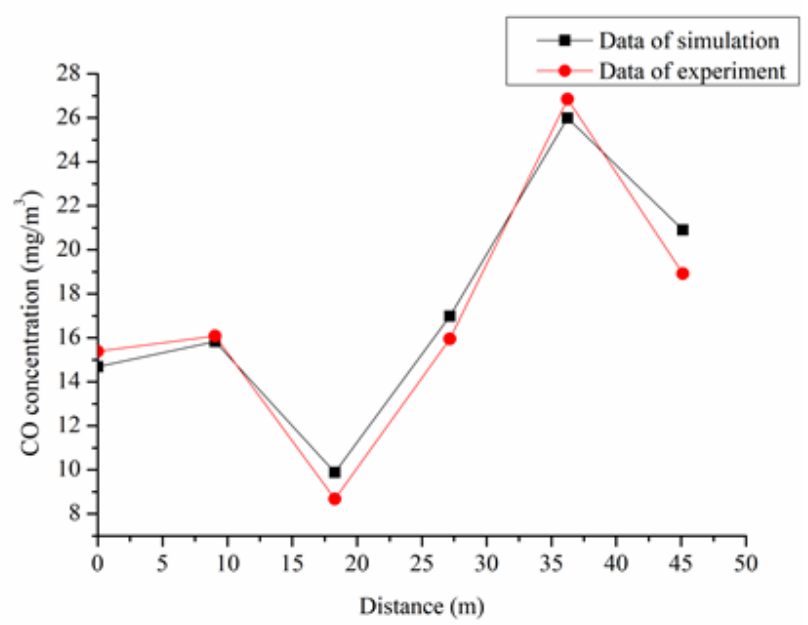

Figure 15. Simulated CO concentrations vs. experimental CO concentrations in aisle 3

\section{Discussion of the ventilation plan}

The key to mechanical ventilation lies in the wind volume, which is positively correlated with the running time of the fan. If the fan works continuously for the entire day, the pollutants can absolutely be emptied, leading to a better air quality. However, the prolonged operation of the fan will produce lots of noises and consumes much energy and money. Thus, it is very important to determine the running time of the fan.

The simulated data show that the $\mathrm{CO}$ concentration in most areas of the garage was below the required level of $30 \mathrm{mg} / \mathrm{m}^{3}$, except the central part. Besides, aisle 1 had a higher CO concentration than the other aisles. Therefore, the next step is to simulate the operation of fan $3 \#$, which is responsible for ventilating aisle 1 . The running time of the fan was determined by the air volume needed to maintain the air quality in the garage:

$$
G=\frac{3600 M}{C_{2}-C_{1}}
$$

where $M$ is the $\mathrm{CO}$ volume; $C_{2}$ is the maximum $\mathrm{CO}$ concentration; $C_{1}$ is the minimum $\mathrm{CO}$ concentration. $M$ can be calculated as: 


$$
M=n \times r \times q \times t
$$

where $n$ is the number of cars; $r$ is the frequency of cars entering the garage; $q$ is the $\mathrm{CO}$ volume released per car; $t$ is the operating time of each car in the garage. The value of $\mathrm{M}$ was calculated as 5,304 $\mathrm{g}$ and the air volume needed to maintain the air quality in the garage was determined as $53,040 \mathrm{~m}^{3}$.

The running time was set empirically to $20 \mathrm{~min}$, three times per day in the rush hours, for the following reasons: the $\mathrm{CO}$ concentration under natural ventilation is only slightly above the required level; it is unknown how long the fan must run before the $\mathrm{CO}$ concentration falls below the required level. Moreover, the outlet of the fan was set as the velocity boundary with the velocity of $6 \mathrm{~m} / \mathrm{s}$. Under these conditions, the author performed a simulation on the mechanical ventilation and analyzed whether the $\mathrm{CO}$ concentration can meet the required level in rush hours. The simulated CO concentrations are illustrated in Figures 16 and 17.

As shown in the figures above, when the fan ran for $20 \mathrm{~min}$, the $\mathrm{CO}$ concentration of the whole garage was controlled effectively, except for some points in aisle 1 $\left(>30 \mathrm{mg} / \mathrm{m}^{3}\right.$ ). Thus, the running time of the fan was extended to $30 \mathrm{~min}$ each time for another simulation. The simulated CO concentrations are displayed in Figures 18 and 19.

The above figures show that, when the fan ran for $30 \mathrm{~min}$, the $\mathrm{CO}$ concentration of each aisle was controlled below the required level. The airflow of one fan in operation is different from that of several fans operating together. However, it is unnecessary to turn on all the fans in the garage at the same time, because the $\mathrm{CO}$ concentration is only slightly above the required level. Considering that aisle 3 had denser $\mathrm{CO}$ than aisle 2, the author continued to simulate the CO concentration in the garages with fan $3 \#$ (aisle 1) and fan 4\# (aisle 3) running for $10 \mathrm{~min}$, three times a day in the rush hours. The simulated $\mathrm{CO}$ concentrations are displayed in Figures 20 and 21.
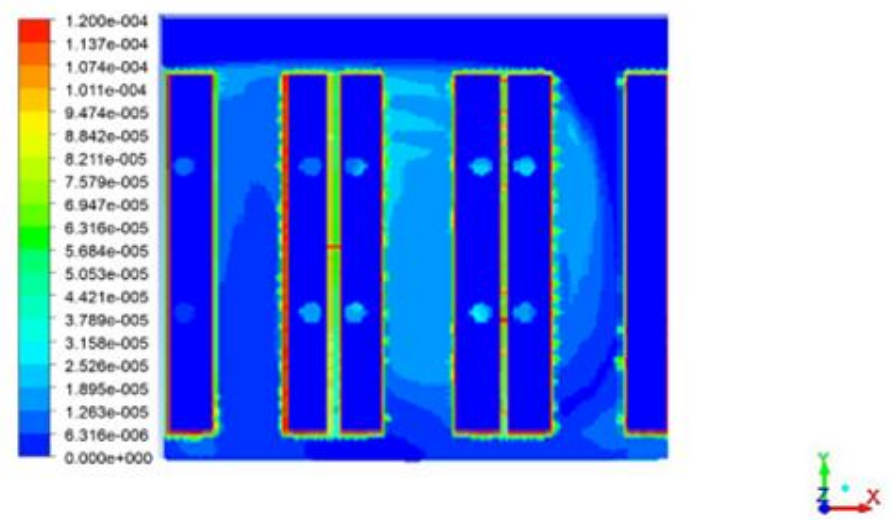

Figure 16. The contour of $\mathrm{CO}$ concentration (20 min; 1 fan) 


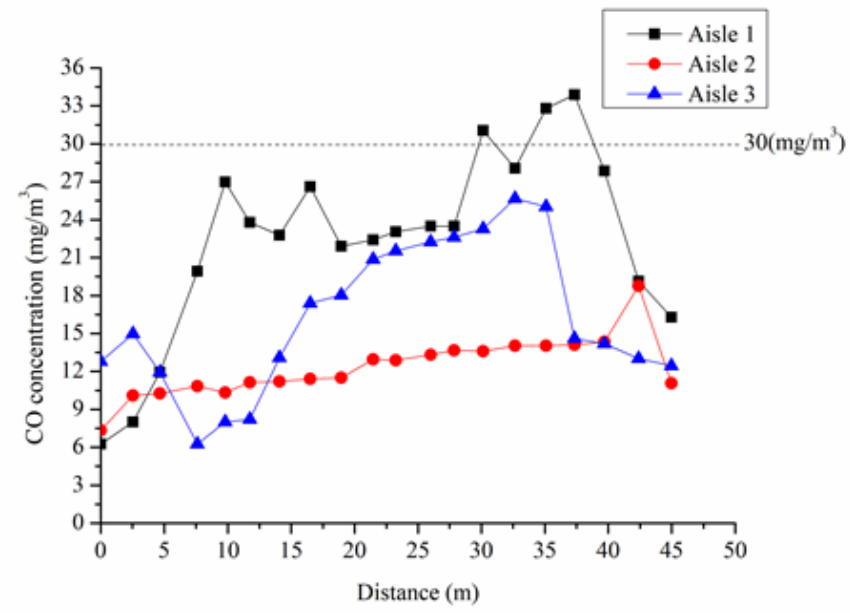

Figure 17. The CO concentration of each aisle (20 min; 1 fan)

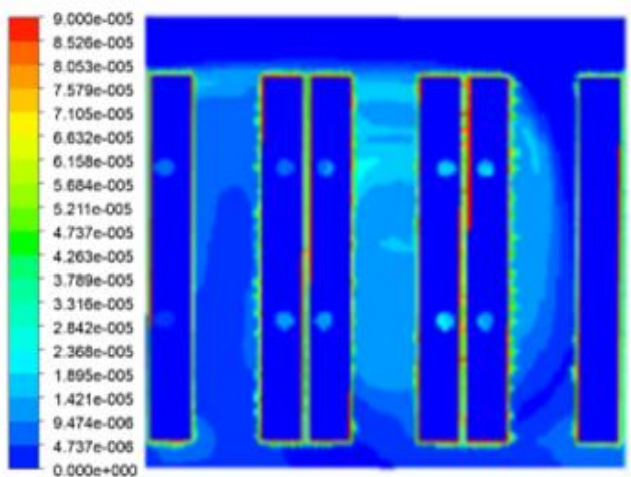

Figure 18. The contour of $C O$ concentration (20 min; 1 fan)

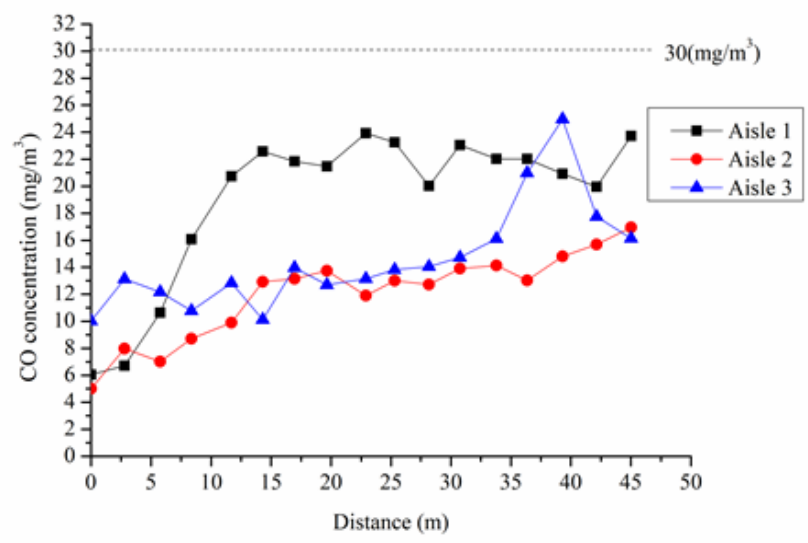

Figure 19. The CO concentration of each aisle (30 min; 1 fan) 

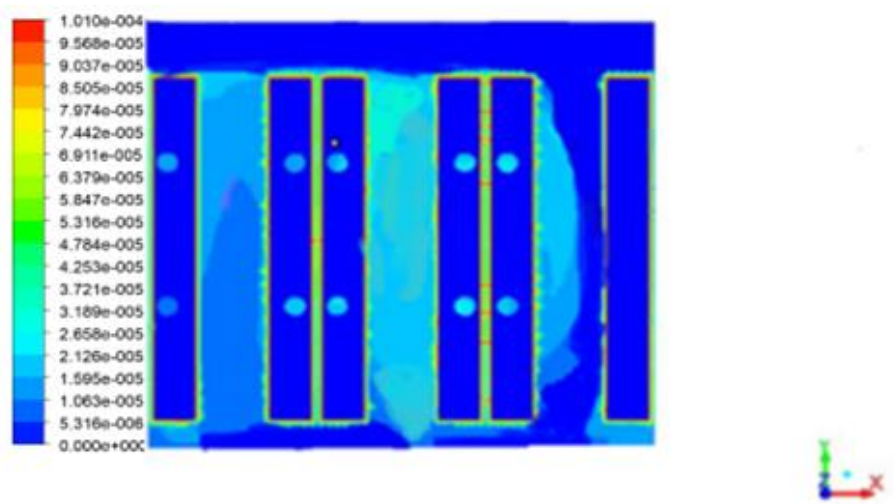

Figure 20. The contour of $\mathrm{CO}$ concentration (10 min; 2 fan)

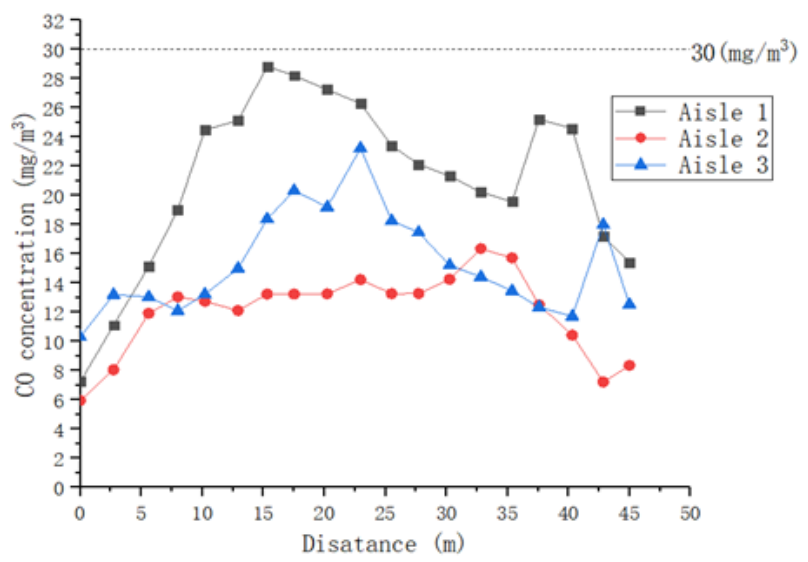

Figure 21. The CO concentration of each aisle (10 min; 2 fan)

As can be seen from the above figures, when the two fans ran 10 min together, the $\mathrm{CO}$ concentration of each aisle was below the required level, indicating the two-fan ventilation plan is satisfactory. The same ventilation effect can also be achieved through the simultaneous operation of 3 or 4 fans for a shorter time. The three-fan or four-fan ventilation plans were not considered because they must be noisier and costlier than the two-fan ventilation plan. Moreover, according to the nameplate of the fans, the power of each fan is about $24 \mathrm{kw}$, it means that this ventilation scheme can save about $1.44 \times 10^{4} \mathrm{~kJ}$ electricity power comparing with another scheme.

Compared with other studies about ventilation in underground garage, the method used in this paper that combining field experiment and simulation is more convenient and effective. In practical cases, more measurements make the analysis more accurate. However, measuring at the necessary area and using the measuring data into the simulation, then carrying out analysis with the finite element method is simpler and effective. Although error of numerical simulation cannot be avoided, confine it in a low range by optimizing the grid and choosing an appropriate algorithm can solve this problem. 


\section{Conclusions}

This paper combines numerical simulation with field experiment to study the pollutant diffusion and ventilation of an underground garage. Firstly, a numerical model was established to explore the diffusion features of pollutants under natural ventilation, and several ventilation plans were designed. After that, the flow field of the garage was investigated with the entrance, exit and ventilation shafts being considered as velocity boundaries, the air in the garage as an incompressible fluid, and the state of air flow as a turbulent flow. The simulated results show that the $\mathrm{CO}$ concentration of the garage was slightly above the required level $\left(30 \mathrm{mg} / \mathrm{m}^{3}\right)$.

Considering the rated capacity of each exhaust fan, the first ventilation plan was designed to let one fan run for $20 \mathrm{~min}$, three times a day in the rush hours. This plan was found to lower the $\mathrm{CO}$ concentration, but not below the required level. Thus, the second plan was designed to increase the running time to $30 \mathrm{~min}$ per time. The simulation results show that the second plan reduced the $\mathrm{CO}$ concentration in each aisle below the required level, indicating that this plan is satisfactory. Similarly, the third plan was simulated with two fans running together for $10 \mathrm{~min}$ per time, and proved satisfactory as well. This plan is enough for the ventilation of the garage because the three-fan or fourfan ventilation plans must be even noisier and costlier. The second and third ventilation plans were further compared. The third plan, i.e. the two-fan plan, was selected as the optimal ventilation plan, because it consumed 33\% fewer power.

Acknowledgements. This research is supported by Applied Basic Research Program of Sichuan Province (Grant No.: 2019YJ0352).

\section{REFERENCES}

[1] Bai, Y., Zeng, Y., Zhang, X., Yan, X., Ruan, L., Zhou, X. (2016): Numerical and experimental study on the flow field induced by a train urgently speeding to the rescue station. - Tunnelling \& Underground Space Technology 58: 74-81.

[2] Bascompta, M., Castanon, A. M., Sanmiquel, L. (2016): A GIS-based approach: influence of the ventilation layout to the environmental conditions in an underground mine. - Journal of Environmental Management 182: 525-530.

[3] Buckley, M. P., Veron, F. (2017): Airflow measurements at a wavy air-water interface using PIV and LIF. - Experiments in Fluids 58(11): 161.

[4] Chen, G. (2001): Determination and control of ventilation at underground garage. Heating, Ventilating \& Air Conditioning 32(1): 62-63.

[5] Choi, J., Hur, N., Kang, S., Lee, E. D., Lee, K. B. (2013): A CFD simulation of hydrogen dispersion for the hydrogen leakage from a fuel cell vehicle in an underground parking garage. - International Journal of Hydrogen Energy 38(19): 8084-8091.

[6] Dokos, S. (2017): Fluid Mechanics. Modelling Organs, Tissues, Cells and Devices. Springer, Berlin.

[7] Hong, K., Wang, X., Zhou, Z., Zhou, S. (2010): Influence of branch tunnels on CO diffusion simulation of main underground powerhouse construction ventilation. International Conference on Biomedical Engineering and Informatics 7: 2654-2657.

[8] Kierat, W., Bivolarova, M., Zavrl, E., Popiolek, Z., Melikov, A. (2018): Accurate assessment of exposure using tracer gas measurements. - Building \& Environment 131: 163-173. 
[9] Kurnia, J. C., Sasmito, A. P., Mujumdar, A. S. (2014): CFD simulation of methane dispersion and innovative methane management in underground mining faces. - Applied Mathematical Modelling 38(14): 3467-3484.

[10] Liu, E., Li, W., Cai, H., Peng, S. (2019a): Formation Mechanism of Trailing Oil in Product Oil Pipeline. - Processes 7: 7.

[11] Liu, E., Lv, L., Ma, Q., Kuang, J., Zhang, L. (2019b): Steady-state optimization operation of the West-East Gas Pipeline. - Advances in Mechanical Engineering 11(8): 1-14.

[12] Liu, E. B., Yan, S. K., Peng, S. B. (2016a): Noise silencing technology for manifold flow noise based on ANSYS fluent. - Journal of Natural Gas Science and Engineering 29(2): 322-328.

[13] Liu, E. B., Yan, S. K., Peng, S. B. (2016b): Large eddy simulation and FW-H acoustic analogy of flow-induced noise in elbow pipe. - Journal of Computational and Theoretical Nanoscience 12(9): 2866-2873.

[14] Liu, E. B., Peng, S. B., Yang, T. W. (2018): Noise silencing technology for upright venting pipe jet noise. - Advances in Mechanical Engineering 10(8): 1-15.

[15] Papakonstantinou, K., Chaloulakou, A., Duci, A., Vlachakis, N., Markatos, N. (2003): Air quality in an underground garage: computational and experimental investigation of ventilation effectiveness. - Energy \& Buildings 35(9): 933-940.

[16] Su, Z. Liu, E., Xu, Y. (2019): Flow field and noise characteristics of manifold in natural gas transportation station. - Oil \& Gas Science and Technology-Revue d'IFP Energies Nouvelles 74: 1-12.

[17] Varga, S., Soares, J., Lima, R., Oliveira, A. C. (2017): On the selection of a turbulence model for the simulation of steam ejectors using CFD. - International Journal of LowCarbon Technologies 12(3): 233-243.

[18] Wang, H., Wang, C., Wang, D. (2017): The influence of forced ventilation airflow on water spray for dust suppression on heading face in underground coal mine. - Powder Technology 320: 498-510.

[19] Wang, X. L., Zhang, Z. Q., Li, T., Liu, X. P. (2009): Dust diffusion simulation in the third layer construction of underground powerhouse. - School of Environmental Science and Engineering Tianjin University (English version) 15(2): 135-139.

[20] Wang, Z., Ren, T. (2013): Investigation of airflow and respirable dust flow behaviour above an underground bin. - Powder Technology 250(12): 103-114.

[21] Wang, Z. Q., Peng, Y., Zheng, J. H. (2016): Computational fluid dynamics simulation of storage temperature field in a non-ventilated underground granary. - Modern Food Science \& Technology 32(1): 170-174.

[22] Widiatmojo, A., Sasaki, K., Widodo, N. P., Sugai, Y., Sinaga, J., Yusuf, H. (2013): Numerical simulation to evaluate gas diffusion of turbulent flow in mine ventilation system. - International Journal of Mining Science and Technology 23(3): 349-355.

[23] Xu, G. (2015): Remote characterization of ventilation systems using tracer gas and CFD in an underground mine. - Safety Science 74:140-149.

[24] Xue, H., Ho, J. C. (2000): Modelling of heat and carbon monoxide emitted from moving cars in an underground car park. - Tunnelling and Underground Space Technology incorporating Trenchless Technology Research 15(1): 101-115.

[25] Yong, C., Xu, P., Hao, Y. (2017): Mechanical performance experiments on rock and cement, casing residual stress evaluation in the thermal recovery well based on thermalstructure coupling. - Energy Exploration \& Exploitation 35: 591-608.

[26] Zhang, G. S., Li, T. T., Luo, M., Liu, J. F., Liu, Z. R., Bai, Y. H. (2008): Air pollution in the microenvironment of parked new cars. - Building \& Environment 43(3): 315-319.

[27] Zhao, Y., Song, X., Wang, Y., Zhao, J., Zhu, K. (2017): Seasonal patterns of pm10, $\mathrm{pm} 2.5$, and pm1.0 concentrations in a naturally ventilated residential underground garage. - Building \& Environment 124: 294-314. 